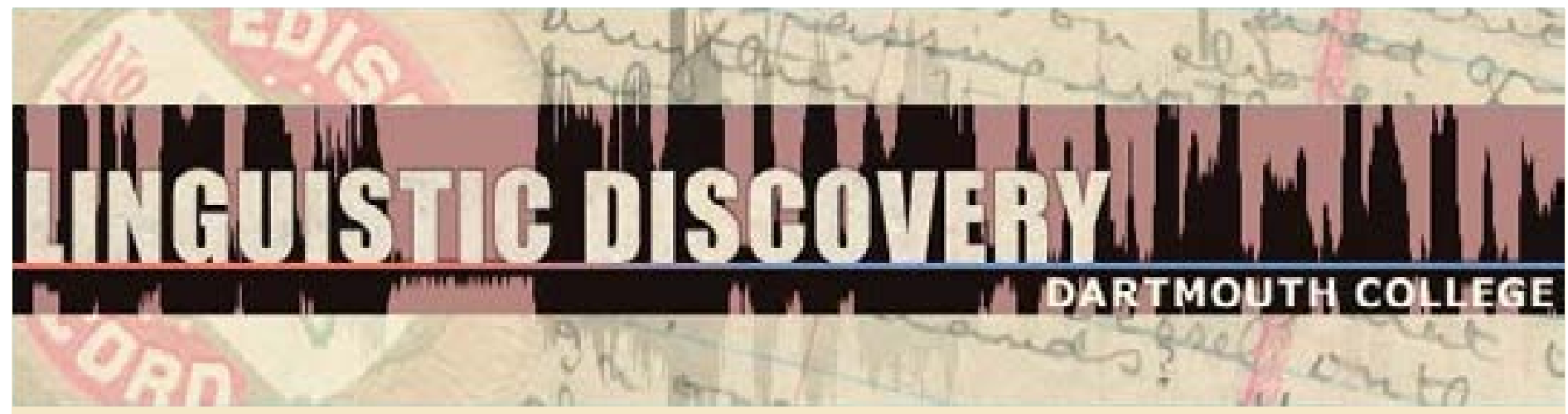

\begin{tabular}{|l|}
\hline Volume 12 \\
Issue 2 \\
2014 \\
\hline
\end{tabular}

\title{
Locative-related Roles and the Argument-Adjunct Distinction in Balinese
}

I Wayan Arka

The Australian National University/ Universitas Udayana

doi: $10.1349 / P S 1.1537-0852 . A .446$

url: http://journals.dartmouth.edu/cgi-bin/WebObjects/ Journals.woa/1/xmlpage/1/article/446

\section{Linguistic Discovery}

Published by the Dartmouth College Library Copyright to this article is held by the authors. CC BY-NC ISSN 1537-0852 


\section{Locative-Related Roles and the Argument-Adjunct Distinction in Balinese \\ I Wayan Arka}

The Australian National University/Universitas Udayana

This paper uses the realisation of locative-related roles in Balinese to show that there is no clear-cut distinction between arguments and adjuncts, supporting the gradient nature of grammatical functions (cf. Croft 2001; Langacker 1987; Aarts 2007). It argues that argumenthood is not wholly a property of a lexical head predicate and that a purely lexically based projectionist approach to syntactic argument structures cannot be maintained. It also explores the effect that the interplay between relevant properties of locatives has on their recruitability as arguments, and a novel argument-index analysis is proposed as a means to distinguish adjuncts from arguments. The analysis makes use of both general and languagespecific morphosyntactic and morphosemantic tests.

Investigation of locative-related roles reveals that certain properties determine their status in the argument-adjunct continuum: thematic, individuated and animate locatives are more argument-like than non-thematic, inanimate and general deictic locatives (in line with Kittilä 2007, 2008; Peterson 2007). Interplay between these properties is shown to affect argument recruitment in Balinese, based on the value of the argument index for a given locative-related role. More generally, there also is evidence that languages vary in whether they allow true adjuncts to be recruited as arguments at all.

\section{Introduction ${ }^{1}$}

This paper discusses the distinction between arguments and adjuncts in Balinese (Austronesian, 3 million speakers, spoken mainly in Bali, Indonesia), focussing on the realisations of locativerelated roles. While Balinese is in general well-studied (Artawa 1994; Clynes 1995; Arka 2003), issues associated with argument-adjunct distinction have not been investigated in any considerable depth in previous studies of this language. The findings reported in this paper reveal some progress in our understanding of the argument-adjunct distinction in Balinese, as well as confirmation of the nature and known complexity of variables involved in determining grammatical relations, in particular animacy, specificity and individuation (Silverstein 1976; Comrie 1989; Kittilä 2008, among others).

Locative-related roles in Balinese are of special interest because they can be realised in a variety of syntactic functions; as arguments (subject, object, and oblique), as well as adjuncts. Balinese has voice and applicative alternations, which provide an opportunity to observe which properties are involved when locative alternations are either permitted or prohibited in specific instances. In addition, Balinese allows multiple locatives in a single clause. This gives an interesting insight into the competition between NPs with identical semantic roles in syntactic

\footnotetext{
${ }^{1}$ This paper was presented at the at workshop on The Argument/Adjunct Distinction Cross-Linguistically at the 44th Annual Meeting of the Societas Linguistica Europae, 8-11 September 2011 Logroño, Spain, and at seminars at the MPI Jakarta Field Station in February 2013, at the Institute for Linguistics Cologne University in April 2013 and at the University of Konstanz. Special thanks go to audiences at the conference and seminars for their feedback, in particular (in alphabetical order) John Bowden, Miriam Butt, David Gil, Nikolaus Himmelmann, Tim Mckinnon, and Frans Plank. Revision was made possible thanks to the 2012 RSAP ANU grant and the Humboldt Foundation, who supported my research stay in Germany.
} 
argument mapping, an area not well explored in the previous research into the argument-adjunct distinction. These questions are discussed in detail in this paper.

The claim verified in this paper is that locative-related expressions in different functions provide evidence for the gradient nature of argumenthood (Langacker 1987; Aarts 2007). On the basis of argument index calculation - a simple, novel means to assess argument status that is further discussed in section 3 - it is shown that there is no clear-cut argument-adjunct distinction. As an argument type close to adjuncts, obliques show mixed characteristics in Balinese. Obliques appear argument-like on the basis of their general properties of argument-structure, whereas on the basis of language-specific behavioural properties, obliques appear adjunct-like. Role thematicity (thematic vs. non-thematic) crosscuts the argument-adjunct distinction, giving rise to different types of arguments and adjuncts. It is shown that thematic adjuncts are more recruitable as arguments than non-thematic adjuncts. The semantic and spatial properties of animacy, relative specificity, individuation and deixis are also important: locatives expressing general space or spatial (deictic) relators or spatial frames, e.g. samping 'side of' and beten 'down', are real adjuncts and as such not recruitable as arguments, while animate locatives are recruitable as arguments. The implication of this study for linguistic theory is that, while it is useful to distinguish arguments (subject, object, obliques) from adjuncts, the two categories are not to be taken as discrete, and that for language-specific purposes, one might have more finegrained categories, capturing intermediate positions such as semi-core and semi-obliques/semiadjuncts. In addition, given that properties such as specificity and animacy may come from syntactic dependents (i.e. they are not always entailed by head predicates), the argument-adjunct status of an XP dependent cannot always be determined by the lexical properties of the head. The distinction is ultimately determined by the interaction of these properties with the properties of the XP dependent. Thus, a purely lexically based projectionist approach to syntactic argument structures cannot be maintained.

The paper is organised as follows. After an overview of Balinese morphosyntax in section 2, the method of assessing argument status is outlined in section 3 . This is followed by the presentation of the main data in section 4, showing the patterns of different realisations of locatives in Balinese and highlighting an array of the underlying semantic-grammatical variables at work. Section 5 provides discussions, addressing the gradient nature of the argument-adjunct distinction and its implication in the conception of syntactic classes and related descriptivetheoretical issues. Final remarks in section 6 highlight the contribution of the present paper and outlines remaining issues for future research.

\section{Balinese Morphosyntax in Brief}

Balinese is an SVO language. The default order exemplified in (1a) shows the subject NP (which is also the default topic) in sentence-initial position. Different word order, often accompanied by a different intonation pattern, marks different information structure. The verb (and its object) can be fronted to a clause-external focus position. The fronted element is also given stress, followed by a pause (indicated by a //) in (1b-c). Example (1b) shows the fronting of VO whereas example (1c), the fronting of the verb only. The structures in both cases are pragmatically marked with the $\mathrm{VO}$ and the $\mathrm{V}$ being contrastively focussed, as indicated by the free translation in English. 
$\begin{array}{lll}\text { (1a) Tiang } & \text { ng-adol } & \text { tanah } \\ 1 & \text { AV-sell } & \text { land } \\ \text { 'I sold (my) land.' } & \end{array}$

(1b) Ng-adol tanah // tiang AV-sell land 1

'Selling (my) land was what I did.'

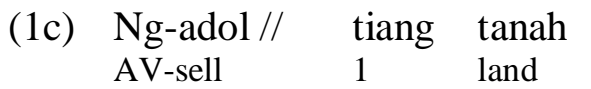

'I SOLD, not bought, land.'
(SVO) (Actor Voice, default)

(VOS) (pragmatically marked)

(VSO) (pragmatically marked)

Balinese shows a well-defined notion of a surface grammatical subject (SUBJ) with evidence coming from properties such as preverbal position, exclusive access to relativisation, raising, control, and fronting as a question word (see Arka 2003 for details).

The grammar of Balinese also accommodates an explicitly definable distinction between direct core (subject and object) arguments, henceforth 'core' arguments, and obliques. Core arguments are characterised by properties such as the ability to launch quantifier float, the ability to provide an antecedent for a resumptive pronoun, the ability to control depictive predicates (with some qualifications), and the ability to be the understood (Actor) argument of imperatives (Arka 2003: chapter 3). These properties are further discussed in section 3 below in relation to argument indexing to determine the argument/adjunct status of locatives.

Of particular significance in the discussion of the argument-adjunct distinction is voice alternation and applicativisation. These related processes provide a test to assess the nature of oblique-adjunct distinction. The crucial point is that a voice type selects a core argument as grammatical subject. An oblique or non-argument is not selectable, and therefore must be promoted first to core status by means of applicativisation. As shall be demonstrated later, locatives are of different kinds and show different degrees of recruitability as arguments, hence providing an insight into their degree of argumenthood/adjuncthood and the nature of the distinction. $^{2}$

Voice alternations in Balinese include AV (actor voice), UV (undergoer voice), PASS (passive) and MID (middle); each is exemplified in (2) with the same verb root diman 'kiss'. A specific voice selects which argument is chosen as Subject. The actor voice (AV) selects A as Subject (2a). As in other Austronesian languages of western Indonesia, Balinese has an UV structure $(2 \mathrm{~b})$ where the patient $(\mathrm{P})$ is subject but the actor $(\mathrm{A})$ remains a core argument. Thus, AV-UV alternation does not alter syntactic transitivity; i.e. a UV alternation is not equivalent to passivisation. ${ }^{3}$ Note that Balinese has its own passive, where the Argument is an oblique, prepositionally marked by teken 'by' in (2c).

\footnotetext{
${ }^{2}$ Voice is central to the discussion of the argument-adjunct distinction because it is through this mechanism that arguments are recruited.

${ }^{3}$ Note that the English translation for $(2 b)$ is intended to keep the information structure of the original Balinese sentence (i.e. Patient is topic) while at the same time the agent is still highly topical and a core argument (i.e. not an oblique). Evidence that the patient Nyoman is grammatically the subject, not a fronted P object, comes from a number of subjecthood tests in Balinese such as relativisation and control; see Arka (2003:8-29) for further details.
} 
(2a) Tiang niman Nyoman.

Actor Voice (AV): A=SUBJ

1 AV.kiss Nyoman

'I kissed Nyoman.'

$\mathrm{A} \& \mathrm{P}$ are core arguments

(2b) Nyoman diman tiang.

Nyoman UV.kiss 1

'Nyoman, I kissed.'

Undergoer Voice (UV): $\mathrm{P}=\mathrm{SUBJ}$

A \& $\mathrm{P}$ are core arguments

(2c) Tiang diman-a teken Nyoman

1 kiss-PASS by Nyoman

'I was kissed by Nyoman'

(2d) Nyoman ajak tiang ma-diman. Nyoman and 1 MID-kiss

'Nyoman and I kissed each other.'

Passive Voice (PASS): $\mathrm{P}=\mathrm{SUBJ}$

$\mathrm{A}$ is Oblique

Middle Voice (MID):

$\mathrm{A} \& \mathrm{P}=\mathrm{SUBJ}$

There are two applicative suffixes in Balinese, -ang and -in, shown in Table 1 and exemplified in (4)-(8). They are each associated with different roles. For the discussion of locative-related roles herein, we are only concerned with -in; see Arka (2003:195-202) for a complete discussion of applicatives in Balinese. As seen, Table 1 shows that the same suffix $-i n$ is used for source/goal/locative roles in Balinese. A wide sense of the term 'locative' is sometime used in this paper to include 'goal' and 'source'. That is, conceptually, the notion of location is part of the interpretation of goal/source (cf. Jackendoff 1990); the end point of a goal path, or the departure point of a source path, is a location.

\begin{tabular}{|l|l|l|l|}
\hline Base & Suff. & Applicative types & Derived argument structures \\
\hline \multirow{2}{*}{ Intransitive } & -ang & Ben, Th & $\begin{array}{l}\text { Transitive (i.e. two terms) } \\
<[\text { base actor], [appl.arg] }>\end{array}$ \\
\cline { 2 - 3 } & -in & Loc & \\
\hline \multirow{2}{*}{ Transitive } & \multirow{2}{*}{-ang } & Ben, Recipient & $\begin{array}{l}\text { Ditransitive (i.e. three terms): } \\
<[\text { base.actor], [appl.arg], [base.non.actor] }>\end{array}$ \\
\cline { 2 - 4 } & Instr & $\begin{array}{l}\text { three-place transitive (i.e. two terms and one non-term): } \\
<<[\text { base.actor], [appl.arg] ><[base.non.actor] }>>\end{array}$ \\
\cline { 2 - 3 } & \multirow{2}{*}{-in } & Source/Goal/Loc & $\begin{array}{l}\text { ditransitive (i.e. three terms): } \\
<[\text { base.actor], [appl.arg], [base.non.actor] }>\end{array}$ \\
\hline
\end{tabular}

The -ang examples are given in (3)-(5) and the -in examples are given in (6)-(8). Each of the examples is given in pairs with (a) showing the non-applicative structure and (b) the applicative counterpart.

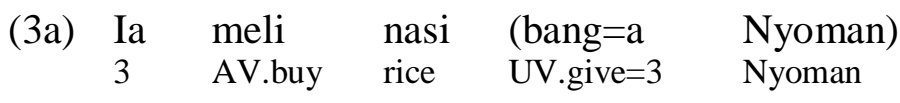

'(S)he bought rice (for Nyoman).' 
(3b) Ia meli-ang Nyoman nasi.

(Ben. appl.)

3 AV.buy-APPL Nyoman rice

'(S)he bought Nyoman rice'

(4a) Ia manteg panak-ne teken buku ento. 3 AV.throw child-3POSS with book that

'(S)he pelted his/her child with the book'

(4b) Ia manteg-ang buku ento sig panak-ne.

(Instr. appl.)

3 AV.throw-APPL book that at child-3POSS

'(S)he threw the book at his/her child'

(5a) Ia demen teken Nyoman

3 happy with Nyoman

'(S)he likes Nyoman'

(5b) Nyoman demen-ang=a .

Nyoman UV.happy-APPL=3

(Stim. appl.)

'(S)he likes/loves NYOMAN'

(6a) Ia meli baas (sig dagang-e ento).

3 AV.buy rice at trader-DEF that

'(S)he bought rice from the trader'

(6b) Ia meli-nin dagang-e ento baas

(Source appl.)

3 AV.buy-APPL trader-DEF that rice

'(S)he bought rice from the trader'

(7a) Ia mempen klambi-ne di tas-e.

3 AV.place shirt-3POSS in bag-DEF

'(S)he placed his/her shirt in the bag'

(7b) Ia mempen-in tas-e klambi.

3 AV.place-APPL bag-DEF shirt

(Loc appl.)

'(S)he placed shirts in the bag'

(8a) Tiang ngadep siap sig anak-e ento 1 AV.sell chicken to person-DEF that 'I sold a chicken to the person.'

(8b) Anak-e ento adep-in tiang siap. person-DEF that UV.sell-APPL 1 chicken

(Goal appl.)

'To the person, I sold a chicken.' 
An important point to note from the applicativisation is the status of the introduced or applied argument. There is good evidence, e.g. from reflexive or quantifier binding (Arka 2003: chapters 6 and 7), to support the analysis that the applied (locative) argument is in the second position in the argument structure list. It is shown in bold in the representation in the last column in Table 1. Being in the second position after the actor, the applied argument is linked to object in the actor voice (AV), and linked to subject in the undergoer voice (UV). When the outcome of the applicativisation is a ditransitive structure, the applied argument becomes the first object of the AV structure. This is exemplified by the beneficiary argument in (3), which is realised as OBJ1 immediately after the verb. The linking can be informally schematised as (9).

$$
\begin{array}{ll}
\text { meli-ang 'AV.buy-APPL } & <\text { agt , ben , th>' } \\
& \text { SUBJ OBJ1 OBJ2 }
\end{array}
$$

Note that the underlying theme, being the third in the list, becomes the second object, structurally immediately following the first object. This is observed in the (b) sentences in (3), (6) and (7). It should be noted as well that the applied argument in the second position after the actor in the argument structure list typically outranks the theme for the linking to subject in the UV. This is exemplified in (8b), in which case the actor tiang ' $I$ ' (1.sg) remains highly prominent syntactically (i.e. a core argument, not an oblique). In short, this structure consists of three core arguments with the applied argument functioning grammatically as subject and the underlying actor and theme core arguments remaining.

Before discussing how applicative alternations apply or do not apply to locative-related roles with different degrees of argument status, the notion of argument index must first be discussed.

\section{Argument Index}

\subsection{Argument index and syntactic classes}

To decide whether a locative is an argument or an adjunct, I adopt a simple methodology called 'argument index', building on Arka (2005). An argument index is an index that indicates the extent to which a syntactic unit can be classified as an argument or an adjunct. The index calculation is based on a range of general properties (e.g. subcategorisation and obligatoriness) and language-specific properties (e.g. marking and quantifier float); see Appendix for the full list. The index is the proportion of argument properties that are satisfied by the dependents of a verb. Its value ranges from 1.00 (definitely a core argument) to 0.00 (definitely an adjunct).

As an illustration, the calculation of the argument index of the passive sentence in Balinese in (2c) is given here. The agent argument of the passive satisfies four out of fourteen argumentrelated properties (listed in Appendix 1): being subcategorised, being related to event participant (i.e. thematic), not modifying the head predicate and possibly undergoing a core alternation; hence it has an argument index of 0.29 (i.e. 4/14).

Previous research on Balinese (Arka 2003, 2005) and the current investigation of locatives reported in this paper reveal that argument index values are in descending order from subject to adjunct. This might have been expected on the conception that syntactic functions form a hierarchy (see footnote 9) with subject being definitely a core argument and that the boundaries between lower-end functions, e.g. between object and obliques or between obliques and adjuncts, are not always clear-cut. The argument index values provide a clear picture of the gradient nature 
of the argument-adjunct dichotomy. This is shown in Figure 1. Note that any index analysis must be done in combination with the traditional description showing (language-specific) evidence for argument/adjunct properties. The novel aspect of this argument index is its general utility in language description, for comparative purposes. It enables us to decide with confidence the syntactic status of a clausal dependent in a given structure and in a given language, e.g. whether it is an object, an oblique or an adjunct, especially in problematic cases. ${ }^{4}$ For example, there has been significant work on the Balinese voice system (and similar Indonesian-type systems in other Austronesian languages), with a debate whether UV should be treated as a kind of passive or not. The answer to this hinges on the status of the underlying actor, whether it is an oblique/adjunct or not. The proposed argument index has provided us with a simple tool to settle it for good: the A of the UV structure is, as seen in Figure 1, definitely a core argument, with an index far higher than an Oblique/adjunct, even higher than the $\mathrm{T}$ (OBJ2) of a ditransitive structure. It cannot therefore be treated as a passive.

\begin{tabular}{|c|c|c|c|c|}
\hline \multirow{6}{*}{ Arguments: } & & & & \\
\hline & $\uparrow 1.00$ & S, A of AV (Subject) & c & A \\
\hline & 0.92 & $\mathrm{R}$ (First Object of a ditransitive structure) & 0 & $\mathrm{R}$ \\
\hline & 0.89 & $\mathrm{P}$ (Object of a transitive structure) & $\mathrm{R}$ & G \\
\hline & 0.79 & A of UV & E & $u$ \\
\hline & 0.67 & I (second Object of a ditransitive structure $L$ & & M \\
\hline \multirow{4}{*}{----} & 0.34 & Oblique goal of 'ask' & & E \\
\hline & 0.29 & Oblique agent of PASS & 0 & $\mathrm{~N}$ \\
\hline & 0.26 & Oblique loc of 'sit' 5 & B & $\mathrm{T}$ \\
\hline & 0.19 & Semi-oblique/adjunct instrument of 'hit' & & \\
\hline---- & 0.07 & ?adjunct locative of 'sleep'; ex. (14) & \multirow{2}{*}{\multicolumn{2}{|c|}{ ADJUNCT }} \\
\hline Adjuncts: & $\downarrow 0.00$ & Adjunct: general or deictic locative & & \\
\hline
\end{tabular}

Figure 1: Argument index values and their syntactic classes in Balinese ${ }^{56}$.

\begin{abstract}
${ }^{4}$ To maximise its utility, the argument index calculation requires a deep understanding of the grammar of the language under investigation. Thus, one should proceed with the traditional methodology in language description, and make use of the argument index as a supplementary tool to enhance the description or analysis. It should be noted that the syntactic status of a clausal dependent (especially those in borderline cases) reveals the complex interplay between the lexical semantics of the head predicate and its dependent. In conjunction with languagespecific resources (e.g., verbal voice/applicative morphology and phrasal marking), the head verb and the dependent co-determine the argument index, i.e., the ultimate status of a dependent. This is the key point that this paper wants to demonstrate.
\end{abstract}

5

Ia negak (di dampar-e)

3 AV.sit at bench-DEF

(OBLloc: 0.26)

'(S)he sat on the bench.'

6

$\begin{array}{lllll}\text { Ia } & \text { ng-lempag } & \text { Nyoman } & \text { (teken/aji } & \text { sampat) } \\ 3 & \text { AV-hit } & \text { Nyoman } & \text { with } & \text { broom }\end{array}$

(Semi-OBLInst: 0.19)

'(S)he hit Nyoman with a broom.' 
The horizontal dotted lines represent approximate fuzzy borders demarcating traditional categories of direct core arguments, obliques and adjuncts. Argument index calculations show that core argument instances in Balinese have index values of over 0.60 , and obliques, of around $0.20-0.40$. In this paper we are only concerned with the oblique argument-adjunct distinction. ${ }^{7}$ We are interested in instances of locatives with argument index values ranging from 0.00 (absolutely adjuncts) to borderline oblique cases; i.e. those that fall into the upper space of the adjunct category, here dubbed 'oblique-adjuncts' for convenience. To facilitate the discussion, argument index values are included in the relevant examples throughout the paper.

\section{Locative-Related Expressions in Balinese and Relevant Properties}

\subsection{Why locatives?}

Locatives and locative-related roles (goal and source) are of interest in the investigation of argument-adjunct distinction for the following reasons. To begin with, they are marked by the same applicative marker. Given their interaction with voice alternations in Balinese, a locativerelated dependent can potentially appear in almost all grammatical functions (subject, object, oblique and adjunct). Their alternations and associated constraints therefore provide clues about the nature of argument-adjunct distinction, and information about the properties involved in it. For example, the goal gua 'cave' of the verb celep 'go (into)', underlined in (10), can appear as an oblique of the intransitive middle verb macelep 'go' in (a), object of the AV transitive applicative nyelepin 'go' in (b), and subject of the UV applicative celepin 'go' in (c).
(10a) Tiang ma-celep [ka gua-ne $]$
1 MID-go.into to cave-DEF
'I went into the cave.'
(PP-OBL; 0.19)
(10b) Tiang nyelep-in [gua-ne]
1 AV.go.into-APPL cave-DEF
'I entered the cave.'
(NP-OBJ; 0.83)
(10c) [Gua-ne] celep-in tiang cave-DEF UV.go.into-APPL 1
(NP-SUBJ; 1.00)
'The cave, I entered.'

Note that the different grammatical realisations of the goal gua-ne 'the cave' correlate with different argument index values. Among the properties that make it a core argument/object in (10b) (with a high argument index of 0.83) are the verbal marking and the categorial realisation of the goal as an NP rather than a PP, its structural position immediately following the verb and its obligatoriness. For example, marking the goal as a PP in (10b) would render the structure in (11) unacceptable:
(11) *Tiang nyelep-in [ka gua-ne]
1 AV.go.into-APPL to cave-DEF
'I entered the cave.'

${ }^{7}$ See Arka (2005) for discussion of the core-oblique distinction. 
Evidence that the goal guane 'the cave' in (10c) is the grammatical subject comes, for example, from relativisation. Only the grammatical subject can be relativised in Balinese, hence the contrast shown in (12). As seen in this example, relativising the sentence-initial goal NP in the applicative structure is fine. In contrast, relativising the corresponding goal PP with the middle verb (i.e. non-applicative) is ungrammatical; compare (12b) with (10a).

$\begin{array}{lllll}\text { [Gua-ne } & \text { ane } & \text { celep-in } & \text { tiang] luwung. } \\ \text { cave-DEF } & \text { REL } & \text { UV.go.into-APPL } 1 & \text { good }\end{array}$

'The cave which I entered is good.'

$\begin{array}{lllll}* \text { [ka } & \text { gua-ne } & \text { ane tiang } & \text { ma-celep] luwung. } \\ \text { to } & \text { cave-DEF } & \text { REL } 1 & \text { MID-go.into good }\end{array}$

FOR: 'The cave which I entered is good.'

It should be noted that applicativisation and voice alternation have a semantic and pragmatic basis and affect transitivity. For example, the same root celep is glossed as 'go.into'. It appears with the middle prefix ma- (macelep) in (10b), in which case it is syntactically intransitive, translated as go in English. The same verbal root appears with the applicative -in (celepin) in (10b-c), giving rise to a transitive verb. Its equivalent in English as shown in the free translation is 'enter'. In addition, the goal in the applicative sentence (10c) is the subject-topic. This is captured by the English translation by using topicalisation. However, it should be noted that the Balinese sentence is not a structure with a topicalised fronted object.

Sentences in (13) provide more examples of goal OBJ-OBL alternations: sampine 'the cow' alternates between OBJ1 in (13a) and OBL in (13b). It should be noted that the alternation is solely due to different kinds of applicativisation (-ang vs. -in) because both sentences are in actor voice. The -in applicative in the AV structure marks the goal as object and -ang marks the displaced theme/instrument as object, cf. Table 1.

\begin{tabular}{|c|c|c|c|c|c|c|}
\hline (13a) & $\begin{array}{l}\text { Pan } \\
\text { Pan }\end{array}$ & $\begin{array}{l}\text { Nerti } \\
\text { Nerti }\end{array}$ & $\begin{array}{l}\text { ngentung-in } \\
\text { AV.throw-APPL }\end{array}$ & $\begin{array}{l}\text { [sampin-ne] } \\
\text { cow-3sPOS }\end{array}$ & padang & (NP-OBJ1; 0.92) \\
\hline
\end{tabular}

Secondly, the locative role is often regarded as being low in the thematic hierarchy. In fact, it is the lowest item in Bresnan's thematic hierarchy (Bresnan and Kanerva 1989). ${ }^{8}$ OBL and

${ }^{8}$ There are different versions of thematic hierarchy in the literature where locatives may not be the lowest. Rappaport Hovav and Levin (2004) provide the following list of different versions of thematic hierarchy; see the references therein:

Agt $>\mathrm{Th} / \mathrm{Pt}>\mathrm{G} / \mathrm{S} / \mathrm{L}$

Aget $>\operatorname{Exp}>$ Th

Agt $>$ Ben $>$ Rec $/$ Exp $>$ Inst $>$ Th $/$ Pt $>$ L

Agt $>$ Pat $>$ Rec $>$ Inst $>$ L $>$ Temp

Agt $>$ Exp $>$ Inst $>$ Pat $>$ G/S/L $>$ time

Agt $>$ Dat $/$ Ben $>$ Pat $>$ L $>$ Inst $/$ Assoc $>$ Mann

Act $>$ Pat $/$ Ben $/ \mathrm{Th}>\mathrm{G} / \mathrm{S} / \mathrm{L}>$ Ben

Agt $>$ Eff $>\operatorname{Exp}>$ L $>$ Th $>$ Pat
(Baker 1997)

(Belletti\&Rizzi 1988)

(Bresnan \&Kanerva 1989)

(Dik 1978)

(Fillmore 1971)

(Givón 1984)

(Jackendoff 1990)

(Van Valin 1990) 
ADJUNCT are also at the lower end in the grammatical function hierarchy (Bresnan 2001). ${ }^{9}$ Given the basic principle of linking theories, which is essentially the harmonious mapping of items between different hierarchies, it is expected that locatives are aligned with obliques or adjuncts by default.

The possibility of different kinds of locatives of the same verb being realised as an oblique or adjunct reflects the nature of the argument-adjunct distinction. For example, different locative instances can appear with the verb pules 'sleep' in (14). All of the underlined locatives of pules 'sleep' are arguably adjuncts, as evidenced by their being optional. In addition, the notion of sleeping, unlike 'sitting', does not necessarily require a location to sleep in. One can sleep while standing. However, the potential argument status of these different locatives is not the same, which is revealed by calculation of their argument indices. The first two (dampare 'the bench' and umahne 'his/her house') appear to be closer to argument status than the last one (alase 'the forest'). This is supported by the fact that the first two locatives allow an applicative alternation whereas the last one does not, as seen in (14b). ${ }^{10}$

$\begin{array}{lll}\text { Tiang } & \text { pules } & (d i \\ 1 & \text { sleep } & \text { at }\end{array}$

$(0.15)$

$\begin{array}{ll}\text { dampar-el } & d i \\ \text { bench-DEF } & \text { at }\end{array}$

(0.07)

$\begin{array}{lll}\text { umah-ne/ } & d i & \text { alas-e) } \\ \text { house-3POSS } & \text { in } & \text { forest-DEF }\end{array}$

(0.00)

'I slept on the bench / at his/her house / in the forest'

Tiang mules-in $\quad \begin{array}{lll}\text { dampar-e / } & \text { umah-ne / ?*alas-e } \\ 1 & \text { AV.sleep-APPL bench-DEF house-3POSS forest-DEF }\end{array}$
'I slept on the bench / at his/her house / ?* in the forest'

The point exemplified in (14) is that locative adjuncts do not form a homogenous group and that it is possible for certain kinds of locative adjunct to be recruited or promoted as a core argument (subject or object). The referents of the three locatives in (14) differ in their spatial size, which feeds into the notions of specificity, generality and affectedness. A large, general space like 'forest' is harder to conceptualise as being affected by the event of sleeping, and is therefore not typically recruitable as an argument. As seen in (14b), the locative 'forest' is treated as a pure adjunct by the verb 'sleep', with an argument index of 0.00 . It cannot participate in applicative alternation, and could only be acceptable with a bizarre meaning in which the person is of such a giant size that their body covers the entire forest. However, if the locative 'forest' appears with other verbs such as tanam 'plant' as in (15), it is easily recruitable as an argument.

The significance of hierarchies including thematic hierarchies in grammar especially in argument realisation and marking has been recognised in the literature. For example, agent is typically the default subject whereas patient is the default object. The realisations of locative-related roles as discussed in this paper are of particular interest as they are neither typical subject nor object. They are typically either PP obliques or adjuncts (by default). They can be expressed as (first) object, however, by applicativisation.

${ }^{9}$ The following are two hierarchies, called accessibility hierarchy in (i) and relational hierarchy in (ii)

i) $\mathrm{S}>\mathrm{DO}>\mathrm{IO}>\mathrm{OBL}>\mathrm{GEN}>\mathrm{OCOMP}$ (Keenan and Comrie 1977)

ii) SUBJ $>$ OBJ $>$ OBJ-theta $>$ OBL-theta $>$ COMPL $>$ ADJUNCT (Bresnan 2001:212).

While the two were postulated on the basis of different grammatical phenomena (e.g. Keenan \&Comrie's hierarchy is for relativisation), they are similar in that obliques are low in the hierarchy (though not the lowest).

${ }^{10}$ Two properties satisfied here: alternation to object (core) by both, and participant-related only by the locative 'bench' not 'house'. 
(15a)

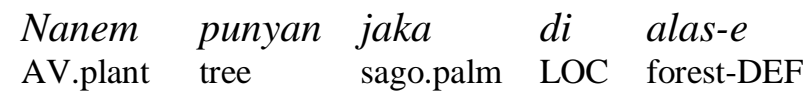

'plant sago/palm trees in the forest'
$\begin{array}{llll}\text { nanem-in } & \text { alas-e } & \text { punyan } & \text { jaka } \\ \text { AV.plant-APPL } & \text { forest-DEF } & \text { tree } & \text { sago.palm }\end{array}$
'populate the forest with sago palm trees'

In short, the property of affectedness is important. There are also other relevant semantic properties, which interact in a complex way, for argument-adjunct distinctions in Balinese. These include animacy, thematicity, individuation and deixis. Each will be discussed and exemplified in the following subsections.

\subsection{Animacy: human locatives and spatial points of reference}

Before we come to the different behaviour of locatives with respect to argument status, it is important to note that Balinese marks locatives differently depending on their animacy. The variation in prepositional marking is shown in (16):

(16) Prepositions and animacy in Balinese:

(a) human/animate locatives: sig/sid 'loc/goal/source'

(b) inanimate as a place/spatial point of reference: $d i$ 'loc', $k a$ 'goal' $u l i$ 'source'

As noted above, animate locatives are marked by sig/sid (depending on the dialect), and this is invariant for locative, goal or source roles. For inanimate locatives, there are three prepositions ( $d i, k a$, and $u l i$ ) for different roles (locative, goal and source respectively).

Animate and inanimate goal-locatives also behave differently with respect to argumentadjunct alternations. Animate goals are argument-like and more readily promoted as arguments, whereas inanimate goals are typically adjuncts. Consider the animate goal anakento 'the child' in (17a), which is marked by sig, not $\mathrm{ka}$. It can alternate with the object in the applicative verb sogokin 'push' in (17b). In contrast, the inanimate goal temboke 'wall' in (18a), which receives the marking $k a$, not sig, cannot alternate to become the object in the applicative verb. We also observe that sentence $(18 \mathrm{~b})$ is unacceptable.

$\begin{array}{lllll}\text { Sogok } & \text { plangkan-e } & \text { sig/*ka } & \text { anak-e } & \text { nto! } \\ \text { push } & \text { bench-DEF } & \text { LOC } & \text { person-DEF } & \text { that }\end{array}$

(Goal)

'Push the bench towards the person.'

(17b) Sogok-in anak-e nto plangkan-e! push-APPL person-DEF that bench-DEF

'Push the bench towards the person.' 


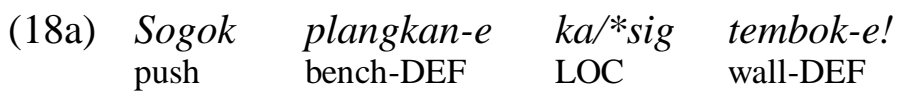

'Push the bench towards the wall.'
*Sogok-in tembok-e plangkan-e!
push-APPL wall-DEF bench-DEF
'Push the bench towards the person/the wall.'

More evidence comes from the alternation of the source-locative shown in (19)-(20). Anake 'the person' in (19a) is an animate source; hence it is marked by sig, not uli. It can alternate to become the object in the applicative structure in (19b). Semere 'the well' is an inanimate source, and therefore marked by uli, not sig. Unlike the source in (19), this inanimate source cannot alternate to become an object, as shown by the unacceptability of (20).

$\begin{array}{lllll}\text { Nyoman } & \text { nyilih } & \text { pipis } & \text { sig/*uli } & \text { anak-e } \\ \text { Nyoman } & \text { AV.borrow money } & \text { LOC } & \text { person-DEF }\end{array}$

(Source)

'Nyoman borrowed money from the person.'

$\begin{array}{llll}\text { Nyoman } & \text { nyilih-in } & \text { anak-e } & \text { pipis } \\ \text { Nyoman AV.borrow-APPL person-DEF } & \text { money } \\ \text { 'Nyoman borrowed money from (the) people.' }\end{array}$

(20a) Nyoman ngedeng tali uli/*sig semer-e Nyoman AV.pull rope LOC well-DEF 'Nyoman pulled out the rope from the well.'

(20b) *Nyoman ngedeng-in semer-e tali Nyoman AV.pull-APPL well-DEF rope 'Nyoman pulled out the rope from the well.'

Such difference in marking based on animacy is widely reported for other languages, typically in relation to the nature of the marking of direct core arguments (ERG/ABS), DOM (differential object marking) and DRM (Differential R marking, where $\mathrm{R}$ is the goal/recipient role of a threeplace predicate (see Dryer 1986; Haspelmath 2007; Kittilä 2008 and the references therein). The basic function of the differential marking is the need to distinguish arguments of a predicate, A vs. P/O (Comrie 1978:379; Dixon 1979:69) and to index or mark the prototypical nature of transitivity, in particular affectedness (Hopper and Thompson 1980; Naess 2004; Kittilä 2008). Viewed from the perspective of linking principles (Bresnan and Kanerva 1989; Manning 1994; Alsina 1996), these are part of a complex mechanism to create harmonious alignment across different layers of hierarchical structures in grammar. The relevance of animacy is broadly represented by Figure 2. It shows that animates are by default aligned to the agent-like core argument (A), whereas inanimates are aligned to the patient-like P. Linking alignment is indicated by a vertical line. Of course, linking and marking can be extremely complex in an individual language. However, the representation in Figure 2 captures the cross-linguistic generalisation that a harmonious linking is the unmarked one. Thus, in a nominative system, a highly animate participant (A) is by default linked to subject (i.e. unmarked), but is specifically marked when it is linked to a non-A/subject role. 


\author{
CORE hierarchy: \\ Role hierarchy: \\ Animacy hierarchy: \\ Figure 2: CORE-ANIMACY alignment
}

To summarize, locatives are low in the thematic hierarchy, and therefore are typically noncore/non-arguments. Balinese locatives show animacy-based differential oblique/adjunct marking (sig vs. $\mathrm{ka}$ ). Since animates are higher than inanimates in the hierarchy, it is not surprising that animate locatives are more readily recruitable as core arguments than inanimate ones in Balinese. This finding provides further support for animacy playing a role in grammar. This has been reported in other languages: for example, ergative marking is optional for animate nouns but obligatory for inanimate nouns in Gooniyandi (Australia, McGregor 1990:319-20). Studies in syncretism (Baerman, Brown, and Corbett 2005:76) reveal that higher animacy arguments (e.g. personal pronoun/human arguments and especially the first/second persons) tend to have exceptional object/accusative case marking. They are prototypical (i.e. unmarked, default) subjects; hence, when they are in object function, they have to be marked distinctively. In contrast, lower animacy arguments, which are prototypically not subjects, tend to have a distinct marker when they do function as the subject.

\subsection{Thematicity and spatial specificity}

Role thematicity is important for the argument-adjunct distinction: thematic locative adjuncts are readily recruited as arguments whereas non-thematic ones are not. ${ }^{12} \mathrm{~A}$ thematic adjunct is an adjunct whose semantic role can potentially be conceptualised as part of an event-internal structure of the predicate. ${ }^{13}$ Following Asudeh and Toivonen (2012), I make a distinction between thematic and semantic roles: a thematic role is the role played by a semantic argument in relation to a predicate. A semantic role, in contrast, is the role played by an individual or an eventuality (event or state), which is not necessarily a semantic argument. Thus, all thematic

\footnotetext{
${ }^{11}$ The animate>inanimate hierarchy is often discussed as part of a larger (more complex) general hierarchy that include other categories such as person $(1>2>3)$, definiteness (definite>indefinite), and nominal types (pronouns $>$ proper names $>$ common nouns), e.g. $1>2>3>$ proper names/human $>$ non-human/animates $>$ inanimates. A language-specific animacy hierarchy may include very specific categories only relevant to a given language where animals are subdivided into finer categories, e.g. in Navajo into large (e.g., bears, horses), medium (e.g., sheep, fox), and small (e.g. squirrels, snakes) (Uyechi 1990 in Bresnan 2001), hence the animacy hierarchy in this language is: humans $>$ animals $>$ insects $>$ natural forces $>$ plants, inanimate objects $>$ abstract notions.

${ }^{12}$ It should be noted that we do not assume that a noun by itself is by default an adjunct, or an argument. It is its structural position and marking in a given context in relation to the head predicate that matters with respect to its syntactic status. However, for the discussion of locatives, we can assume that a locative role is generally not a core argument, since a core argument is typically thematically an agent and/or patient. The discussion of alternative realisations of locatives as part of the investigation of the distinction between argument and adjunct naturally may focus more on the possible promotion of locatives to argument status. The reverse process, namely the demotion of an argument to adjunct status, is often associated with the core roles, e.g. the agent demoted to become an adjunctoblique in passivisation. This is not the focus of the present paper, however.

${ }^{13}$ For empirical properties of adjuncts (in contrast to arguments) in Balinese, see Appendix 1.
} 
roles are semantic roles whereas the reverse is not true. A scene-setting general adjunct, e.g. in the forest as in In the forest they slept overnight is a non-thematic locative semantic role.

The thematic-semantic vs. non thematic-(non)semantic distinction crosscuts the argument vs. adjunct distinction, giving rise to the classification shown in Figure 3. The dotted double-arrow lines represent dichotomies in a space with no clear-cut boundaries in between. Of particular interests are thematic vs. non-thematic locatives, which can populate spaces in cells B and D as adjuncts, and cell $\mathrm{A}$ as arguments. ${ }^{14}$

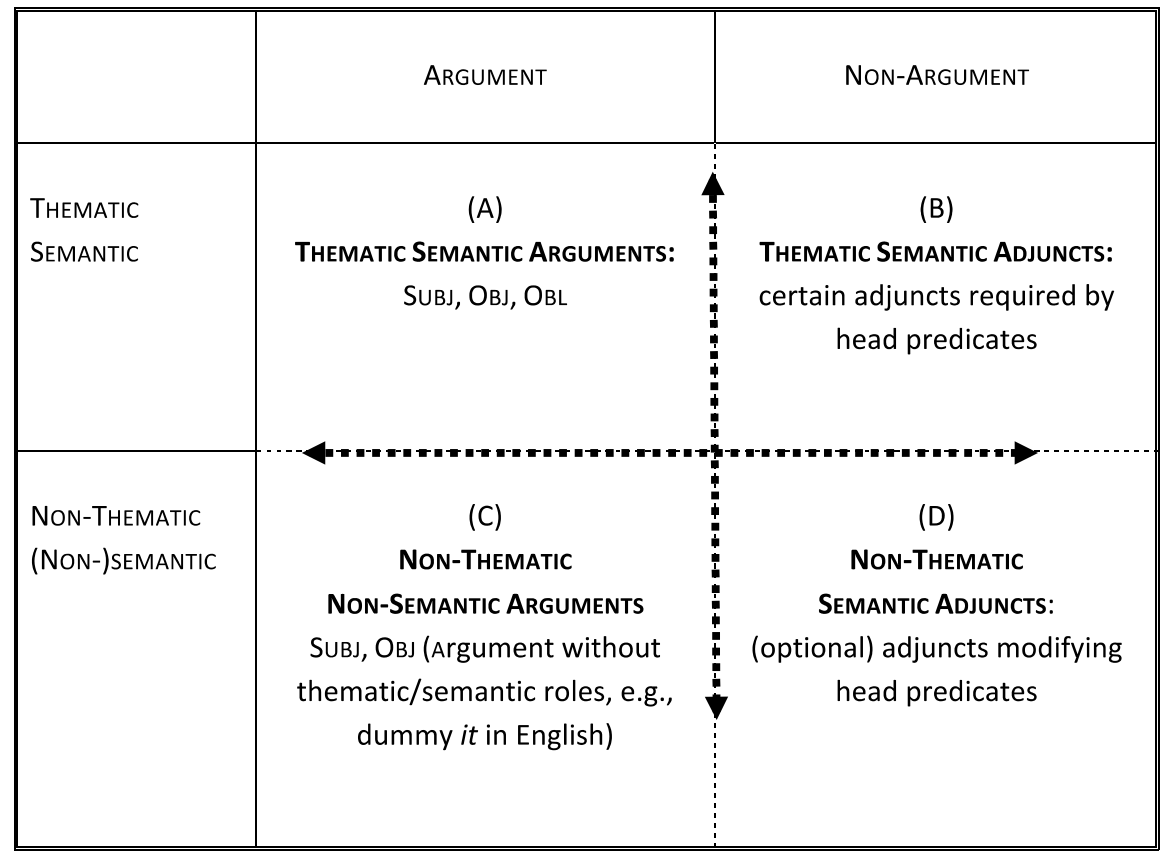

Figure 3: Thematicity and argument-adjunct distinction

There is evidence that thematic locative adjuncts (cell B) are construable as event-internal locatives, and are hence more argument-like than their non-thematic adjuncts (cell D). Role thematicity often interacts with spatial specificity of the location; that is, whether or not the location is conceptually individuated and compact, e.g. with specific or clear boundaries. Such a location is typically relatively small or narrow in its spatial size. For example, as shown in (14), the locatives with the verb pules 'sleep' are of different types, ranging from more or less spatially individuated specific locations such as 'bench' and 'house', to a scene-setting, general, less-individuated space 'forest'. Investigation into their argument index values (shown in example (14)) suggests that, while they are all locative adjuncts, only the first spatially specific ones are thematic, and thus recruitable as arguments in the applicative verb.

Further evidence for the role of spatial specificity in the recruitability of adjunct locatives as an argument comes from cases of multiple locatives appearing in the same sentence. The most specific and individuated one wins out as the thematic locative. Consider (14), repeated here as (21a), where two locatives 'on the bench' and 'at his/her house' co-occur in the sentence. As can be seen, the more specific locative 'the bench' wins out as an argument, recruitable as a

\footnotetext{
${ }^{14}$ For simplicity, since the focus of this paper is on locatives in cells A, B and D, which are all semantic roles, throughout the paper, shorter labels, such as thematic locative or thematic adjunct are used, rather than the longer ones, such as thematic semantic locative or thematic semantic adjunct.
} 
core/subject argument in the UV applicative structure (21b). As a result of this competition, the more general locative 'house' fails to be recruited as an argument, as evidenced from the unacceptability of (21c) and (21d), in which this locative is subject and object, respectively.

(21a) Tiang pules di dampar-e di umah-ne
1 sleep at bench-DEF at house-3POSS
'I slept on the bench at his/her house.'

(21b) Dampar-e pules-in tiang di umah-ne bench-DEF UV.sleep-APPL 1 at house-3POSS 'The bench I slept on at his/her house.'

(21c) *Umah-ne pules-in tiang di dampar-e house-3POSS UV.sleep-APPL 1 at bench-DEF ??'His/her house I slept at on the bench.'

\begin{tabular}{|c|c|c|c|c|}
\hline ?*Tiang & mules-in & umah-ne & $d i$ & dampar-e \\
\hline & AV.sleep-APPL & house-3 & POSS & bench-DEF \\
\hline
\end{tabular}

There is an important point here regarding thematic role competition in grammatical function linking. In particular, the Balinese data highlights an area of role linking related to the argumentadjunct divide that has not previously been investigated in depth. While there has been a considerable body of work on thematic hierarchy and on linking in the literature (Rappaport Hovav and Levin 2004, and the references therein), the focus has been on the competition between distinctly structured thematic roles (e.g. agent vs. beneficiary vs. theme), or macro-roles (actor vs. undergoer) in their mapping onto surface core grammatical relations. The degree of thematicity and competition within a single role category, e.g. between two locatives in the borderline cases discussed in this paper, has not been well explored. While early theories of case/semantic role and grammatical relations, such as Fillmore's Case Grammar (Fillmore 1968; Cook 1989), dealt with similar role competition, the relevant semantic roles are mainly at the high end of the hierarchy, namely agent vs. instrument.

Complicating this issue is the fact that there remains no clear consensus on precise thematic hierarchies. For example, in Lexical-Mapping Theory (Bresnan and Kanerva 1989; Bresnan and Moshi 1990) the role of locative is the lowest item in the hierarchy, whereas in other versions, such as RRG (Foley and Van Valin 1984; Van Valin and LaPolla 1997), it is higher up (see footnote 8). Furthermore, there is disagreement about the theoretical status and extent to which such roles actually represent the syntactic argument structures and semantic properties that they are claimed to reveal (e.g. the issue of the uniqueness of theta roles in the argument structure (Chomsky 1981:36)). In theories that adopt parallel layers of structures, such as LFG (Bresnan 2001; Dalrymple 2001; Falk 2001), there is no one-to-one correspondence between thematic roles and surface syntactic functions. Even in Jackendoff's (1990) semantic structure, in which prominence is built in and plays out in the mapping of roles onto syntax (though not it one-toone fashion), the precise nature of the competition between roles of the same type (e.g., two locatives) and its effect on their recruitability and linking to a syntactic position appears to have been overlooked. 


\subsection{Affectedness and individuation}

Affectedness and individuation are two salient related properties relevant for argument-adjunct distinction: a highly individuated locative is more easily construed as affected or acted upon than a general, poorly individuated one. ${ }^{15}$ Hence, as discussed earlier, 'house' is conceptually more individuated (e.g. with clear physical boundaries) and therefore potentially more argument-like than general wide locatives such as 'forest', 'city' or 'market'. Certainly, the verb with which a locative appears also contributes to the overall conception of affectedness, which ultimately determines the syntactic status of the locative. Consider the following intransitive verb macelep 'go into' (in middle voice) (22a) appearing with either locative warung 'kiosk' or peken 'market'. The first locative is conceptually more individuated than the second one. Apart from the fact that they are clearly optional (indicated by placing them in brackets), inspection of their argument index values shows that both are indeed adjuncts (i.e. with argument index values of below 0.20 ). Only the first one (warung; argument index of 0.14 ) is, however, easily recruitable as an argument; construable as being affected by the event of 'entering'. It can become the subject in the applicative verb in the resultative construction in (22b). The locative peken 'market', in contrast, cannot be easily recruited as an affected applied locative argument.

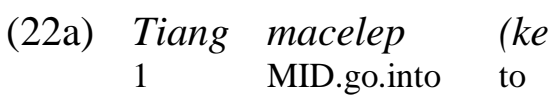

$(0.14)$

(individuated)

\section{warung-ne / kepeken-e)}

kiosk-DEF to market-DEF

(0.00)

(collection of entities)

'I went into the kiosk / the market.'
Warung-nel??Peken-e
celep-in
kiosk-DEF/market-DEF
UV.go.into-APPL
tiang uug
1 damaged
'The kiosk/??market was entered by me (and as a result) it was damaged.'

Of course, being 'individuated' alone is not enough to pass this depictive resultative test, since affectedness is tied to core-patient-argumenthood in the grammar; that is, the locative is required to be promoted to the patient-core argument by means of applicativisation as in (14b). The point is that a locative, while in its default realisation as an adjunct, has some inherent property (in this case, individuation) that makes it more argument-like and patient-like, where patienthood is a prototypical property of an argument rather than an adjunct.

As mentioned earlier, the exact nature of argument/adjunct status is a matter of degree, and is construction-specific. The property of spatial specificity discussed in an earlier section provides a case in point. While in example (22) above, warung 'kiosk' has been proven not to be a pure adjunct, it may well be a pure adjunct at other times, i.e. an event-external adjunct. This variability is surely determined by the head predicate. However, in addition to the entailment in relation to the head verb, the syntactic status of a locative is also determined constructionally whether or not there is a more specific/individuated locative present in the sentence. Consider the double locative constructions in (23), where the verb is the same (sleleg 'lean'). In (23a), the

\footnotetext{
${ }^{15}$ The notion of individuation of entities is defined in terms of certain semantic properties such as number, countability, concreteness, referentiality and definiteness; see Hopper and Thompson (1980). Individuation is a matter of degree; e.g. a singular concrete definite entity is more individuated than a plural indefinite entity.
} 
locative tembok 'wall' is more specific than warung 'kiosk'. It therefore wins out as a thematic locative, and is recruitable as an argument. It then participates in the applicative alternation, as seen in (23b), forcing the more general locative warung 'kiosk' to be a real adjunct, not recruitable as an argument (see the unacceptability of (23c). In the absence of a more specific locative, 'the kiosk' is predictably thematic, and can be made subject in the applicative UV verb; hence the contrast between (23c) and (23d).

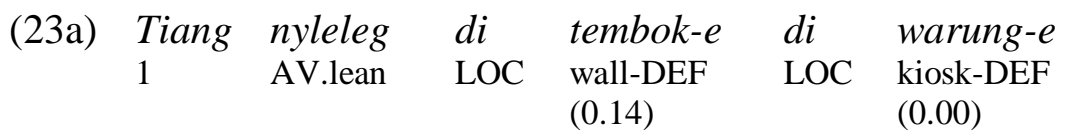

'I leaned against the wall in the kiosk.'

(23b) Tembok-e sleleg-in tiang di warung-e wall-DEF UV.lean-APPL 1 LOC kiosk-DEF 'I leaned against the wall in the kiosk.'

(23c) *Warung-e sleleg-in tiang di tembok-e. kiosk-DEF UV.lean-APPL $1 \quad$ LOC wall-DEF

(23d) Warung-e sleleg-in tiang kiosk-DEF UV.lean-APPL 1

'I leaned against the kiosk.'

To conclude, whether a given locative is a thematic or non-thematic adjunct (i.e. argument-like and recruitable as a core argument or not) is construction-specific. It is associated with event construal that involves the interaction of properties such as individuation, specificity (particularly in double locatives) and affectedness. Cross-linguistic research findings in functional grammar have revealed that individuated nouns are prototypical event participants, realised as syntactic arguments (Hopper and Thompson 1980). Individuation correlates with cognitive salience, often related to the topicality of nominal referents; that is, being perceptually and cognitively salient, typically concrete, durable and spatially compact (Givon 2005:142). In relation to the argumentadjunct divide, the behaviour of the Balinese locatives discussed in this subsection appears to have a good cognitive-conceptual basis.

\subsection{Word class and spatial deixis}

The syntactic status of a locative is also determined by the semantic-syntactic category of its expression: word class (either as a noun, typical for an argument, or adverb, typical for an adjunct). To complicate the matter, spatial deixis appears to matter too. This is also true for English; e.g. I put the book on the table vs. I put the book there. The PP locative in the first sentence is clearly an oblique argument whereas the adverb there in the latter sentence is not. It is adjunct-like, called 'argument-adjunct' by Van Valin (2005:23).

Balinese locatives also behave differently depending on their word-class expressions, which are also often related to spatial deixis. First, consider (24) and (25); both have the same predicate jaang 'put'. The locatives are, however, expressed in different categories: by a PP (with a nonspatial non-deictic noun), kotak 'box' in (24), or by a deictic spatial adverb dini 'here'/ditu 'there', or deictic spatial noun duur 'above/over' in (25). While all of these locatives are 
thematic (i.e. event-internal, part of the meaning of jaang 'put'), only the non-spatial non-deictic noun locative kotak 'box' in (24a) is treated as a clear oblique argument. Evidence for this comes from (24b), which shows that it can undergo applicativisation. As a peripheral unit, its argument index is relatively high (0.34), typical for an oblique. The deictic locative counterparts ditu 'there' and duur 'above' in (25a) are, in contrast, syntactically adjuncts, as evidenced from their inability to undergo applicativisation (25b). Its argument index is very low, although it is not zero (0.10). Note that $(25 \mathrm{c})$ is only acceptable only on a different interpretation, in which duur 'above' is understood as an ordinary noun 'head', not a deictic nominal, as shown in the translation.

(24a) Tiang ngejaang pipis $\left[d i \quad \begin{array}{ll}\text { kotak-e] } & \text { (Loc-OBL: 0.34) } \\ 1 & \text { AV-put money LOC box-DEF }\end{array}\right.$
'I put money in the box.'

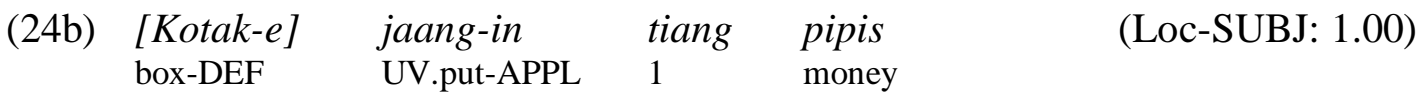

'I put money in the box/on top of or above the box/there.'
(25a) Tiang ngejaang pipis ditu/ di duur (Loc-ADJ: 0.10)
1 AV-put money there LOC top
'I put money there / above there (upstairs).'

(25b)

$\begin{array}{lllll}\text { ?*ditu / } & \text { duur } & \text { jaang-in } & \text { tiang } & \text { pipis } \\ \text { top } & \text { above } & \text { UV.put-APPL } & 1 & \text { money }\end{array}$

'I put money up there/upstairs.'

$\begin{array}{llll}\text { (25c) } & \begin{array}{l}\text { Duur-ne } \\ \text { top-3POSS }\end{array} \text { put-APPL } & 1 & \text { tiang } \\ \text { money }\end{array}$

'I put money on his/her head.'

Spatial deixis items expressing goal or source (kema 'to.there', mai 'toward.here') are treated as adjuncts and are not recruitable as arguments, even though they are arguably thematic. Consider the contrast in (26) where the human goal-locative is an oblique whereas the spatial deictic adverb kema is not. Kema cannot be promoted to the first object in the applicative -in verb in (26b).

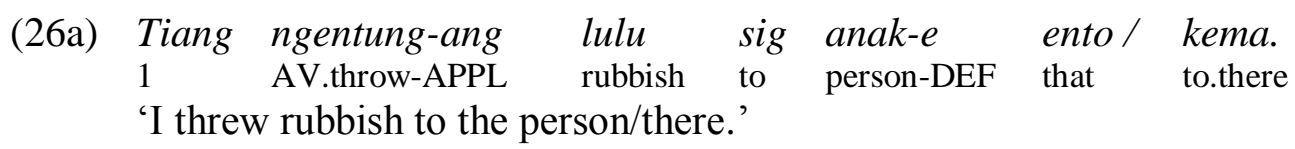

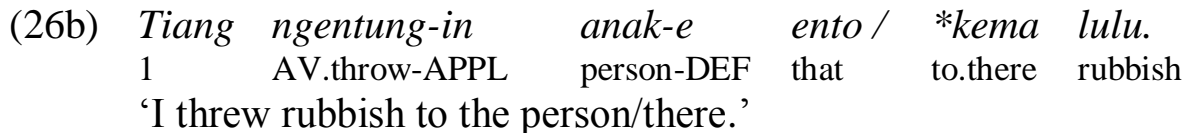

The same pattern is observed for the non-nominal deitic item mai 'toward.here' (where the speaker is): 


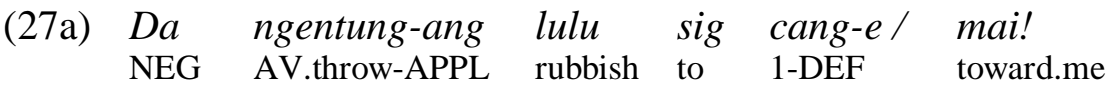
'Don't throw rubbish at me/toward me.'

\begin{tabular}{|c|c|c|}
\hline cang / & ?*mai & $\begin{array}{l}\text { entung-in- } a \\
\text { UV.throw-APPL }\end{array}$ \\
\hline
\end{tabular}

'Don't throw rubbish at me/toward me.'

However, a deictic pronoun/determiner like ene 'this' or nto 'that' can be linked to a locative argument of the verb jaang 'put' as seen in (28). There is no corresponding PP locative oblique/adjunct di ene 'LOC this' or di nto 'LOC that' in Balinese. This indicates that the /d/ segment in dini/ditu 'here/there' might have historically been the captured locative preposition di.
(28a) Tiang nyaang-in ene/nto pipis
1 AV.put-APPL this/that money
'I put money in this/that.'
(28b) Ene/nto jaang-in tiang pipis
This/that UV.put-APPL 1 money
'I put money in this/that.'
(Loc-OBJ: 0.92)
(Loc-SUBJ: 1.00)

The acceptability of the deictic ene/nto 'this/that' in (28) indicates that deixis alone cannot be the main constraint on the alternation here. Rather, it is a deictic meaning in combination with the other properties, namely syntactic category (i.e. word class: nominal or not) and also individuation. But being a nominal alone is not enough, because the spatial deictic items like duur 'the space above/over X' and batan 'the space below $\mathrm{X}$ (where $\mathrm{X}$ is by default the speaker) are nouns. In other words, what distinguishes the deictic determiner (which is a sub-class of nominal) ene/nto 'this/that' from the spatial nominal duur/batan 'above/below' is that the determiner refers to a contextually definite individuated entity with clear boundaries in space. Duur 'the space above (the speaker)' (25a), or beten 'the space below (the speaker)', is an open space without clear boundaries; hence it is non-individuated. Including a definite/possessive morpheme, e.g. -ne '3POSS/DEF', switches duur to an ordinary noun meaning 'the top/head of $\mathrm{X}$ '. Then, the locative is no longer deictic in meaning. It is now an individuated definite entity, which therefore makes it recruitable as an argument as seen in (25c). Non-nominal spatial items like kema 'toward there', mai 'toward here', dini 'here', and ditu 'there' are adjunct-like, and so not recruitable as arguments.

To conclude, the different behaviours of deictic locatives as thematic arguments and thematic adjuncts can be attributed to a combination of their grammatical categories (nominal or not) and the semantic property of individuation in space.

\section{Discussions}

\subsection{A cline with more than one variable at work}

I have argued that the syntactic status of a locative-related role as an argument or adjunct is construction-specific, with more than one variable at work. Locatives fall in different places on 
the argument-adjunct continuum, ranging from absolute adjuncts at one end to thematic semiobliques (or semi-arguments) at the borderline area. Inspection of their argument index values supports this idea.

I have shown that this spectrum of locative types reflects a complex interplay between thematicity (associated with the head predicate's semantics) and other properties (animacy, specificity, individuation, affectedness and deixis) in a given context. This section will highlight the point that there is more than one variable at work, and that the exact degree of argument or adjuncthood is construction-specific. This raises a theoretical issue regarding the nature of syntactic status assignment to an oblique argument in the argument structure, or subcategorisation frame.

Consider the examples in (29) where all structures have the same verb meli 'buy'. They differ only in the properties associated with the source-locative PP: general not-so individuated nonhuman 'the market' (a), more specific individuated non-human 'the kiosk' (b) and individuated human 'the person'.

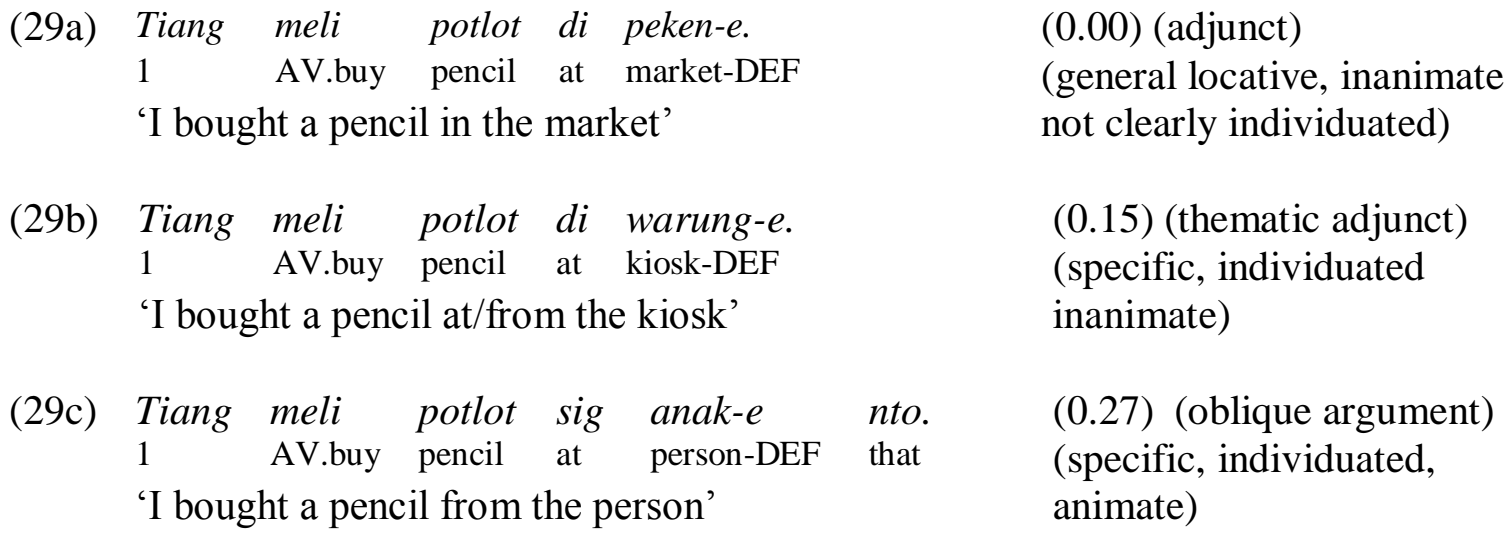

As seen from their argument index values, they are not of the same syntactic types. The locative is an absolute adjunct in (29a), a thematic adjunct in (29b), and a clear argument in (29c). One piece of evidence that separates (a) from (b) and (c) is applicativisation. As seen in (30), applicativisation is impossible in (30a) but possible in (30b) and (30c).

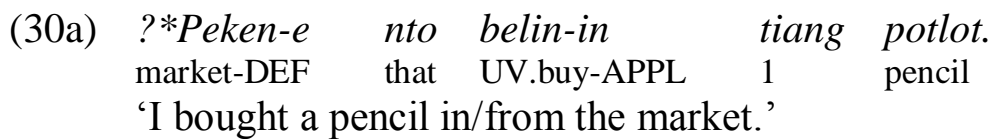

$\begin{array}{lllll}\text { (30b) Warung-e } & \text { nto } & \text { belin-in } & \text { tiang } & \text { potlot. } \\ \text { kiosk-DEF } & \text { that } & \text { UV.buy-APPL } & 1 & \text { pencil }\end{array}$

'I bought a pencil in/from that kiosk.'

$\begin{array}{lllll}\text { (30c) } & \text { Anak-e } & \text { nto belin-in } & \text { tiang } & \text { potlot. } \\ \text { person-DEF } & \text { that UV.buy-APPL } & 1 & \text { pencil }\end{array}$ 'I bought a pencil from the person.'

While 'the kiosk' in (29) is a thematic adjunct, relatively close to being an argument (it has an argument index of 0.15), its argument index drops to an absolute zero when it appears in a double locative construction in the presence of a more specific locative, as in (31). 
$\begin{array}{llllllll}\text { (31a) Tiang } & \text { meli } & \text { potlot sig anak-e } & \text { nto di warung-e } & \text { nto. } \\ & 1 & \text { AV.buy pencil at person-DEF that at kiosk-DEF } & \text { that }\end{array}$ 'I bought a pencil from the person in the kiosk.'

Anak-e nto belin-in tiang potlot di warung-e nto. person-DEF that UV.buy-APPL 1 pencil at kiosk-DEF that 'I bought a pencil from the person in that kiosk.'

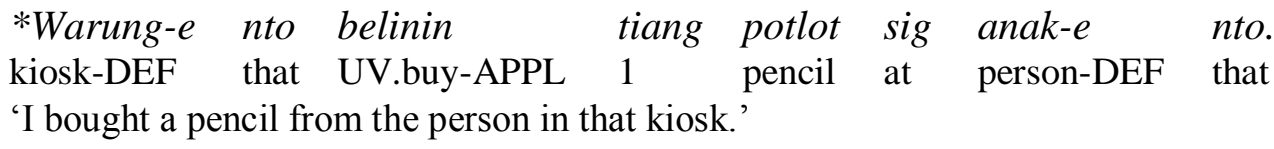

Anakento 'the person' is a highly specific, salient, individuated locative participant-source and wins out over the locative warung 'kiosk' in the competition for argumenthood.

To sum up, a thematic locative can be an oblique or adjunct. Its actual syntactic status is determined by the combination of all properties (predicate and dependents) in a specific structure in a given structural context. Together, this constructional empirical point and the related issue of the fuzziness of the argument-adjunct divide raise problems with the purely lexically driven conception of syntactic argument structure where syntactic units have discrete classes (SUBJ, OBJ, OBL, ADJUNCT), as well as the assignment of syntactic status. In particular, they call into question the conception that an argument's status (e.g. locative as an OBL) is determined in the lexicon and projected to syntax. I now turn to these issues regarding wider typological and theoretical concerns.

\subsection{Syntactic classes and their relevant properties}

We have seen throughout this paper that there is strong evidence for the clinal nature of the argument-adjunct divide, and that the ultimate status of the same locative PP as an oblique, a thematic adjunct, or a pure adjunct is determined by a complex interplay of a number of properties in a given structural/constructional context. In fact, my earlier work on the core vs. oblique distinction in Balinese (Arka 2005) also reveals a broader picture of the fuzzy boundaries between syntactic classes, supported by argument index evidence (see Figure 1).

Capturing the points discussed in this paper, and also incorporating what we know from the literature about the semantic properties involved, we can represent the argument-adjunct distinction as part of the larger, structured dichotomies with no clear-cut boundaries shown in Figure 4. The vertical dotted lines represent fuzzy boundaries while the horizontal lines with double arrows represent a continuum.

The semantic categories (thematicity, animacy etc.) are shown in Figure 4, where the horizontal line in relation to the dotted vertical line dividing oblique and adjunct, the central focus of this paper. Of course, they are also relevant for distinguishing the other syntactic classes such as direct core and oblique arguments, but these are not the primary concern of this paper. 


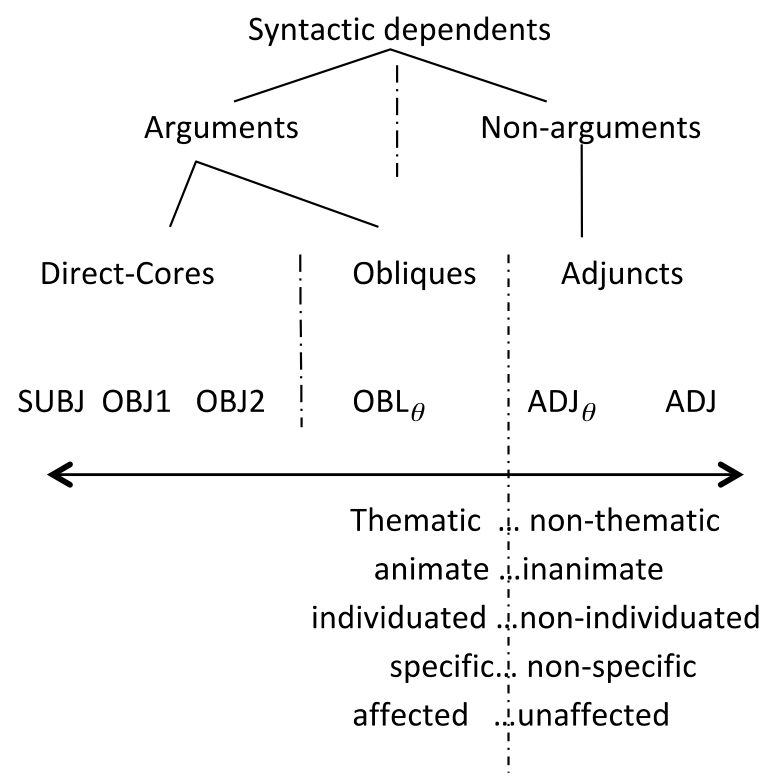

Figure 4: Argument-adjunct gradience and the relevant semantic properties.

This representation is intended to reflect a hierarchy (with the left items being more prominent than the right items across categories), which accounts for the patterns discussed in this paper regarding the realisations of locatives. That is, on the basis of semantics-syntax mapping (and related marking) regulated by harmonious prominence matching, items on the left (i.e. higher in the hierarchy) tend to align by default. Thus, a locative that is thematic, individuated, and potentially affected would get expressed as an argument, whereas a locative that is non-thematic, non-individuated, and not potentially affected would be an adjunct.

\subsection{Descriptive and theoretical issues}

Classifying syntactic classes into arguments (subject, object, and obliques) and adjuncts is important for descriptive, analytical and theoretical purposes. Indeed, it is fundamental in certain linguistic theories such as LFG and HPSG. The gradient nature of syntactic categories discussed in the previous sections poses descriptive and theoretical challenges.

Descriptively, there is no doubt that the labels 'argument' and 'adjunct' are useful analytical tools in language description. The distinction has been taken for granted, and its precise nature is not often questioned or investigated in depth. However, at any stage of describing a grammar, a decision about the syntactic status of a dependent has to be made. Given the clinal nature of argumentood (or adjuncthood) where certain roles are not absolute adjuncts nor obliquearguments (as demonstrated by locative realisations), the question is whether or not we should maintain the two-way classification of syntactic units as arguments or adjuncts. If not, what descriptive label is appropriate for them? For descriptive purposes, it is surely good to capture the precise details of the distinction between syntactic classes. However, we do not want to proliferate categories unnecessarily, with the risk of losing the big picture and the ability to generalise. Keeping this in mind, it is perhaps desirable to use descriptive labels referring to classes in between argument and adjunct. In the literature, different (typically hybrid) labels have been proposed, e.g. oblique-adjunct, argument-adjunct, or a-adjunct (Grimshaw 1990; Van Valin 2005, among others). The term semi-argument or semi-adjunct is adopted here. This is a 
descriptive label used for convenience for an adjunct that has some quantity of argument properties or an argument (oblique) with some quantity of adjunct properties.

Theoretically, the fact that the argument and adjunct distinction is not clear-cut potentially poses a challenge to theories such as LFG (Bresnan 2001; Dalrymple 2001; Falk 2001) and HPSG (Pollard and Sag 1994; Sag, Wasow, and Bender 2003) where syntactic classes are discrete: a syntactic unit is either inside or outside the subcategorisation list. In other theories such as Cognitive Construction Grammar (Langacker 1987; Goldberg 1995; Croft 2001; Iwata 2008, among others), the distinction is expected to be a gradient because it is a product of interaction between grammatical constructions with various degrees of distinctness, and argument/adjunct labels are simply used for convenience (Langacker 2009:25).

Furthermore, the facts of locative expressions in Balinese clearly show that syntactic status as argument or adjunct is not purely lexically determined, providing support for a constructionist model of analysis. This is at odds with the projectionist view adopted in certain theories such as LFG, HPSG and Minimalist frameworks, where syntactic argument structures are projected (i.e. determined) by the lexical (head) predicate. This is certainly not to deny the fact that the head predicate is crucial in shaping the syntactic argument structure, but it is not always enough. The point is that a purely lexically driven syntactic argument structure is untenable, because it cannot account for the counterexamples in (29), which show the differing syntactic status of locatives associated with the same predicate. Empirically specific fillers of dependents supply certain properties (animacy, word class, individuated reference, etc.), which determine the ultimate configuration of a syntactic argument structure. In short, syntactic argument structure is constructed by information coming both from the lexical head and specific dependents in a given context, a stance consistent with Construction Grammar.

\section{Final Remarks: Conclusion and Future Research}

This paper has discussed locative-related expressions and argument-adjunct distinction in Balinese. Alternative expressions of locatives and related constraints, mainly those associated with applicativisation, have revealed the gradient nature of this distinction. They also demonstrate that an array of semantic properties is relevant for the distinction, namely thematicity, animancy, individuation, specificity, affectedness and deixis. These interact with the grammatical property of whether the locative has nominal status. While most of these properties are known in the literature to be also related to global transitivity (Hopper and Thompson 1980), case marking and alignment (Silverstein 1976; Butt 2006; Haspelmath 2007; Kittilä 2007; 2008, among others), this paper is the first, to my knowledge, to provide a detailed examination of the complex interplay of the variables that affect the fluidity of argument-adjunct divide. In addition, the manner in which spatial deixis, in combination with syntactic class, constrains the argument/adjunct classification of a locative has not been scrutinised in the literature before.

Another contribution of this paper is the simple methodology used in the investigation. A straightforward and novel measure called argument index has proven helpful for probing the degree of argumenthood or adjuncthood of a syntactic dependent. This has enabled us to make progress in assessing and comparing the syntactic status of items, and to produce insightful discussions covering a broader perspective. In this paper, we have implemented the argument index to compare locative items within the same language. The same methodology is in principle applicable to cross-linguistic comparative studies of equivalent or different items. This leaves interesting avenues for future research on argument-adjunct distinction across languages. 
Cross-linguistic studies of the argument-adjunct distinction are of great interest. They will help to uncover further evidence about this fundamental division and to answer the important question of whether such a distinction is universal (if one believes in the existence of 'linguistic universals'). Such investigation would lead to a better understanding of the nature of the distinction either in a particular language or cross-linguistically. A quick survey of languages that show locative applicativisation, as reported in Peterson (2007), suggests that there is some variation, although the promoted locatives are typically thematic dependents, e.g. goal-locatives of verbs 'go' or 'throw', or stative locatives with the verb 'sit' or 'lie' as in (32) from Kalkatungu, an Australian Aboriginal language. However, a non-thematic locative can possibly be recruited as an argument object in Kichaga (33), or subject/pivot in Tagalog (34).

(32) Thuku-yu nu-ntiyi kulapuru. (Kalkatungu) dog-ERG lie-TR blanket

'The dog lay on the blanket.'

(Blake ex.5.36b in Austin (2005 [1996]))

$$
\begin{array}{llll}
N \text { - } a-i-l y i-i-a & m-r i-n y i & k \text {-elya } & \text { (Kichaga) } \\
\text { FOC-1s-PR-eat-APP-FV } & \text { 3-homestead-LOC } & \text { 7-food }
\end{array}
$$

'He is eating food at the homestead.'

(Bresnan \& Moshi 1990:148-9)
Kinain-an ni Maria ng kanin ang mesa. PERF.eat-DV GEN Maria LINK rice NOM table.
(Tagalog)
'The table was a place of eating rice of Maria' (La Polla and Poa 2005)

Facts from Kichaga (33) and Tagalog (34) clearly show that there is a great deal variation in the degree of recruitability of low-end (i.e. non-thematic) adjuncts as arguments across languages. Recall that Balinese, unlike Tagalog (while belonging to the same family), only allows thematic locative adjuncts to be recruitable as arguments. That is, they are treated like argument obliques, which are then promoted to core argument status by means of applicativisation. Indeed, more studies are needed to uncover the extent of the variation.

Most studies in applicativisation also reveal similar semantic motivations, such as affectedness and animacy, in addition to discourse forces such as topicality (2007). However, locative applicativisation has an unusual function in at least one language, Haya, as seen in (35). The non-applicative structure in (35a) has an allative reading (i.e. a locative goal reading) whereas the applicative counterpart (35b) has a non-allative (stative) locative reading, as the translation shows. It is unclear whether affectedness is also part of the meaning in (35b). This type of subtle meaning difference is one property that needs to be further investigated for future research.
n-ka-gw’ ómúnju
(Haya)
1-TENSE-fall house
'I fell into the house.' (Hyman and Duranti 1982: 234 in Peterson 2007:49)
n-ka-we-el' ómúnju
1-TENSE-fall-APPL house
'I fell in the house.'

(35b) 
Another important property that needs further cross-linguistic exploration is multiple occurrences of locatives. It is demonstrated in Balinese that the most specific/individuated locative wins out as the most recruitable argument, and this argument can participate in applicativisation. Studies of similar cases in other languages that allow alternative argument realisations with applicative stacking (i.e. double/multiple affixes on the verbs) would be significant. Previous studies on this topic often include instances of different applicative combinations, e.g. benefactive and locative applicatives, or instrument and locative applicatives (Samkoe 1992; Peterson 2007:2002). This is exemplified in (36). Stacking of two of the same applicative affixes is also attested, e.g. as seen in example (37) from Huastec (a Mayan language). While it is generally agreed that the order of applicative morphemes bears some relation to the order of the derivational processes, the precise analysis and theory for this remain controversial, e.g. whether the morpheme ordering is syntactic, as formulated in the Mirror Principle (Baker 1985), ${ }^{16}$ or morpho-lexical (Alsina 1999).

$\begin{array}{llll}\begin{array}{l}\text { Úmwáana } \\ \text { child }\end{array} & \begin{array}{l}\text { y-iicar-i-yé-ho } \\ \text { he-sit-APPL-ASP-APPL }\end{array} & \begin{array}{l}\text { intebe } \\ \text { chair }\end{array} & \begin{array}{l}\text { umugabo. } \\ \text { man }\end{array}\end{array}$

'The child is sitting on the chair for the man.' (Samkoe 1994:215)
Tu $\quad$ nuju-tzi-tzi- $\varnothing \quad t-a$
$1 / 2 \mathrm{~s}$
sell-APPL-APPL-PFV
bitziim-al
horse-pos
(Huastec)
'I sold your horse for you/for him' or
(Samkoe 1994:17)
'I sold you/him your horse.'

Finally, turning to theoretical implications of the present study, we can highlight how the gradient nature of the argument-adjunct divide poses a challenge to certain theories such as LFG or HPSG, which operate on the assumption that this distinction (or any distinction among major syntactic classes such as SUBJ vs. OBJ/COMP vs. ADJUNCT) is discrete. Recall that our findings from Balinese locative realisations support the idea that syntactic argument structure must be ultimately constructed by the interplay between information from the head predicate and from syntactic dependents. It is argued that a purely lexically driven projection of argumentstructure is untenable. The logical consequence of this is to incorporate ideas from Construction Grammar into the LFG analysis. This is in theory possible, but the precise details of such an analysis are yet to be determined in future work.

\section{Appendix: Calculating Argument Indices}

The argument index is calculated on the basis of the general/cross-linguistic and languagespecific defining properties. The cross-linguistic defining properties are shown in Table 2, and the language-specific properties for Balinese are shown in Table $3 .{ }^{17}$ See Arka (2005) for a

\footnotetext{
${ }^{16}$ The Mirror Principle (Baker 1985:375) states that “[m]orphological derivations must directly reflect syntactic derivations (and vice versa)."

${ }^{17}$ The defining properties shown in Table 2 are the most common cross-linguistic generalizations. It should be noted that there may be 'language-specific exceptions'. For example, while adjuncts in English are generaly in line with the properties shown in the table, there are instances where they can be obligatory. This kind of 'subcategorised adjunct' (Dowty 2003:39) is exemplified below with the verb behave:

(a) Johnny behaved badly.

(b) *Johnny behaved. (Acceptable only with a different meaning for behave)
} 
detailed discussion of the properties. The index is calculated as follows. A score of 1 is given if a relevant property is satisfied by a syntactic dependent; or else, 0 if it is not satisfied, 0.5 if it is partly satisfied. Thus, if there are 10 core properties identified in a given language, and if a dependent satisfies all of them, the argument index is 1.00 (i.e. 10/10, an index of 1.00). The dependent is therefore absolutely a core argument. In contrast, if none is satisfied (i.e. 0/10, an index of 0.00 ), the dependent is definitely an adjunct. ${ }^{18}$

\begin{tabular}{|c|c|c|c|c|}
\hline & & \multicolumn{2}{|c|}{ ARGUME } & $\begin{array}{l}\text { NON } \\
\text { ARGUMENT }\end{array}$ \\
\hline & DEFINING PROPERTIES & CORE & OBLIQUE & ADJUNCT \\
\hline i. & Subcategorised for? & Yes & Yes & No \\
\hline ii & Obligatory? & Yes & Not always & No \\
\hline iii. & $\begin{array}{l}\text { Participant-related? } \\
\text { (a) main participant } \\
\text { (b) peripheral }\end{array}$ & $\begin{array}{l}\text { Yes } \\
\text { (a) }\end{array}$ & $\begin{array}{l}\text { Yes } \\
\text { (b) }\end{array}$ & No \\
\hline iv. & $\begin{array}{l}\text { Thematically generalised,possibly } \\
\text { unspecified }\end{array}$ & Yes & No & No \\
\hline v. & $\begin{array}{l}\text { Semantic role (coding) } \\
\text { determined/assigned by the head } \\
\text { predicate? (a) directly (b) } \\
\text { Pcaseneeded }\end{array}$ & $\begin{array}{l}\text { Yes, } \\
\text { directly }\end{array}$ & $\begin{array}{l}\text { Partly yes; } \\
\text { typically } \\
\text { (P)case } \\
\text { needed }\end{array}$ & No \\
\hline vi. & Modifying the predicate? & No & No & Yes \\
\hline
\end{tabular}

Table 2: General characterisations of argument status (core, oblique and adjunct)

\footnotetext{
${ }^{18}$ The core index calculation assumes that the core properties are of equal status. I have investigated whether core properties in Indonesian and Balinese listed in Tables 2 and 3 may have some kind of ranking, but found no conclusive result. It remains to be investigated further whether this is indeed the case, and/or whether other languages may show evidence for relative prominence among core properties. I leave this for future research.
} 


\begin{tabular}{|c|c|c|c|c|}
\hline & DEFINING PROPERTIES & $\stackrel{\text { ARGUM }}{\longleftarrow}$ & & $\stackrel{\text { NON ARGUMENT }}{\longrightarrow}$ \\
\hline & & CORE & OBLIQUE & ADJUNCT \\
\hline i. & Categorial marking & DP/NP & $\mathrm{PP}$ & $\begin{array}{l}\text { Not necessarily } \\
\text { DP/NP/PP }\end{array}$ \\
\hline ii. & Quantifier Float & YES & $\mathrm{NO}$ & $\mathrm{NO}$ \\
\hline iii & $\begin{array}{l}\text { Topicalisation (of } \\
\text { possessor phrase/with } \\
\text { resumptive pronoun) }\end{array}$ & YES & NO & $\mathrm{NO}$ \\
\hline iv & Depictive predicates & YES & $\mathrm{NO}$ & $\mathrm{NO}$ \\
\hline $\mathrm{v}$ & $\begin{array}{l}\text { Elided (=zero) in } \\
\text { imperatives }\end{array}$ & YES & NO & $\mathrm{NO}$ \\
\hline vi & $\begin{array}{l}\text { Promoted to direct core } \\
\text { arguments via } \\
\text { applicativisation? }\end{array}$ & N/A & YES & $\begin{array}{l}\text { a) YES (for 'thematic } \\
\text { Adjuncts') } \\
\text { b) NO (for non-thematic } \\
\text { Adjuncts) }\end{array}$ \\
\hline vii. & $\begin{array}{l}\text { Binding: ability to bind a } \\
\text { core argument }\end{array}$ & Yes & NO & $\mathrm{NO}$ \\
\hline viii. & $\begin{array}{l}\text { Structural positions: } \\
\text { (a) fixed, A-position, } \\
\text { (b) not fixed, non-A position }\end{array}$ & (a) & (b) & (b) \\
\hline
\end{tabular}

Table 3: Language-specific characterisations of argument status in Balinese.

\section{References}

Aarts, Bas. 2007. Syntactic gradience. Oxford: Oxford University Press.

Alsina, Alex. 1996. The role of argument structure in grammar: evidence from Romance.

Stanford: CSLI.

----. 1999. Where's the mirror principle? The Linguistic Review 16/1.1-42.

Arka, I Wayan. 2003. Balinese morphosyntax: a lexical-functional approach. Canberra: Pacific Linguistics.

-----. 2005. On the distinction between Core and Oblique arguments in the Austronesian languages of Indonesia. Paper read at The ALT VI (Association for Linguistic Typology) conference, at Padang, Indonesia, July 21-25, 2005.

Artawa, I Ketut. 1994. Ergativity and Balinese syntax. PhD dissertation, La Trobe University. Asudeh, Ash, and Ida Toivonen. 2012. Copy raising and perception. Natural Language and Linguistic Theory 30.321-380.

Austin, Peter. 2005 [1996]. Causatives and applicatives in Australian Aboriginal languages. The dative and related phenomena, ed. by Kazuto Matsumura and Tooru Hayasi, 165-225. Tokyo: Hitsuji Shobo.

Baerman, Matthew, Dunstan Brown, and Greville G. Corbett. 2005. The syntax-morphology interface: a study of syncretism. Cambridge: Cambridge University Press.

Baker, Mark C. 1985. The mirror principle and morphosyntactic explanation. Linguistic Inquiry 16.373-416.

Bresnan, Joan. 2001. Lexical functional syntax. London: Blackwell.

Bresnan, Joan and Jonni M. Kanerva. 1989. Locative inversion in Chichewa: a case study of factorization in grammar. Linguistic Inquiry 20.1-50. 
Bresnan, Joan and L. Moshi. 1990. Object asymmetries in comparative Bantu syntax. Linguistic Inquiry 21/2.147-185.

Butt, Miriam. 2006. Theories of case. Cambridge: Cambridge University Press.

Chomsky, Noam. 1981. Lectures on government and binding theory. Dordrecht: Foris.

Clynes, Adrian. 1995. Topics in the phonology and morphosyntax of Balinese. PhD dissertation, Australian National University.

Comrie, Bernard. 1978. Ergativity. Syntactic typology: Studies in the phenomenology of language, ed. by Winfred P. Lehman, 329-394. Austin: University of Texas Press.

----. 1989. Language universals and linguistic typology. London: Blackwell.

Cook, Walter Anthony. 1989. Case grammar theory. Washington, DC: Georgetown University Press.

Croft, William. 2001. Radical construction grammar. Oxford: Oxford University Press.

Dalrymple, Mary. 2001. Lexical functional grammar. New York: Academic Press.

Dixon, R. M. W. 1979. Ergativity. Language 55.59-138.

Dryer, Matthew S. 1986. Primary objects, secondary objects, and antidative. Language 62/4. 808-845.

Falk, Yehuda N. 2001. Lexical-functional grammar. Stanford: CSLI.

Fillmore, Charles J. 1968. The case for case. Universals in Linguistic Theory, ed. by Emmon Bach and Robert T. Harms, 1-88. New York: Holt, Rinehart, and Winston.

Foley, William A. and Robert D. Van Valin. 1984. Functional syntax and universal grammar. Cambridge: Cambridge University Press.

Givon, T. 2005. Context as other minds: the pragmatics of sociality, cognition and communication. Amsterdam: John Benjamins Publishing Co.

Goldberg, Adele E. 1995. Constructions: a construction grammar approach to argument structure. Chicago: University of Chicago Press.

Haspelmath, Martin. 2007. Ditransitive alignment splits and inverse alignment. Functions of Language 14/1.79-102.

Hopper, Paul and Sandra Thompson. 1980. Transitivity in grammar and discourse. Language 56.251-299.

Iwata, Seizi. 2008. Locative alternation: a lexical-constructional approach. Amsterdam: John Benjamins.

Jackendoff, Ray. 1990. Semantic structures. Cambridge, Massachusetts: MIT Press.

Kittilä, Seppo. 2007. On the encoding of transitivity-related features on the indirect object. Functions of Language 14/1.149-164.

----- 2008. Animacy effects on differential Goal marking. Linguistic Typology 12/2.245-268.

La Polla, Randy J. and Dory Poa. 2005. Direct and indirect speech in Tagalog. Paper presented at the Workshop on Direct and Indirect Speech, Research Centre for Linguistic Typology, La Trobe University.

Langacker, Ronald. 1987. Foundations of cognitive grammar, Vol. 1: Theoretical prerequisites. Stanford: Stanford University Press.

Manning, Christopher D. 1994. Ergativity: argument structure and grammatical relations. PhD dissertation, Stanford University, Stanford.

Næss, Åshild. 2004. What markedness marks: the markedness problem with direct objects. Lingua 114.1186-1212.

Peterson, David A. 2007. Applicative constructions. Oxford: Oxford University Press. 
Pollard, Carl, and Ivan A. Sag. 1994. Head-driven phrase structure grammar. California: CSLI Publications, Stanford and University of Chicago Press.

Rappaport Hovav, Malka, and Beth Levin. 2007. Deconstructing thematic hierarchies.

Architectures, rules, and preferences: Variations on themes by Joan W. Bresnan, ed. by Annie Zaenen, Jane Simpson, Tracy H. King, Jane Grimshaw, Joan Maling, and Christopher Manning. CSLI Publications, Stanford, CA, 385-402

Sag, Ivan A., Thomas Wasow, and Emily M. Bender. 2003. Syntactic theory : a formal introduction Stanford: Center for the Study of Language and Information.

Samkoe, Lori M. 1994. Mapping multiple applicatives. MA thesis, Department of Linguistics, Simon Fraser University.

Silverstein, Michael. 1976. Hierarchy of features and ergativity. Grammatical categories in Australian languages, ed. by Robert M. W. Dixon, 112-171. Canberra: Australian Institute of Aboriginal Studies.

Van Valin, Jr., Robert D. 2005. Exploring the syntax-semantics interface. Cambridge: Cambridge University Press.

Van Valin, Jr., Robert D. and Randy J. LaPolla. 1997. Syntax. Structure, meaning and function. Cambridge: Cambridge University Press.

Author's Contact Information:

I Wayan Arka

Linguistics, CHL, College of Asia and the Pacific

Australian National University

Fellows Road, ACT 2600

Australia

wayan.arka@anu.edu.au 